\title{
PRÁTICAS ESCOLARES NO ENSINO PRIMÁRIO PÚBLICO BRASILEIRO NO INÍCIO DO REGIME REPUBLICANO
}

C. B. AZEVEDO
$\begin{gathered}\text { Universidade Federal do Rio Grande do Norte } \\ \text { crislaneazevedo@yahoo.com.br }\end{gathered}$
Artigo submetido em agosto/2016 e aceito em agosto/2016
DOI: $10.15628 /$ holos.2016.4705

\section{RESUMO}

Este trabalho está ligado ao projeto "História da escolarização no Rio Grande do Norte (século XX)". Dedica-se à investigação acerca da educação escolar no Rio Grande do Norte ao longo do século XX, com ênfase nos grupos escolares: sua organização, seus professores, sua cultura escolar, suas relações com a normatização, entre outros aspectos. Dessa forma, dedica-se a pesquisar as relações entre o poder instituído e aquilo que efetivamente foi experimentado pelas instituições de ensino e seus sujeitos. A pesquisa sobre as práticas não é simples, requer o trabalho com amplo e diversificado acervo documental. Assim, foram levantadas diferentes fontes de pesquisa tendo em vista a análise de diferentes aspectos relativos ao cotidiano de escolas públicas norterio-grandenses. Este artigo toma por base um recorte deste projeto de pesquisa, tratando, dessa forma, das práticas escolares presentes no cotidiano dos grupos, com atenção especificamente a: passeios extraclasse, uso de materiais pedagógicos diversificados, orientações de Higiene, exercícios físicos, e, festas escolares.

PALAVRAS-ChAVE: Ensino Público, Século XX, Rio Grande do Norte

\section{PRACTICAL SCHOOL IN PRIMARY EDUCATION IN BRAZILIAN PUBLIC SYSTEM BEGINNING OF REPUBLICAN}

\begin{abstract}
This work is linked to the project "school of history in Rio Grande do Norte (XX century)". Dedicated to research about school education in Rio Grande do Norte during the twentieth century, with emphasis on school groups: their organization, their teachers, their school culture, its relations with the standardization etc. Thus, dedicated to research the relationship between the established power and what was actually experienced by the educational institutions and their subjects. Research on the practice
\end{abstract}

is not simple, requires working with large and diverse documentary collection. So they were raised different sources of research in order to analyze different aspects of the daily life of public schools North Rio Grande. This intervention is based on a cut of this research project, trying thus of school practices in the daily routine of the groups, with specific attention: extracurricular trips, use of diverse teaching materials, hygiene guidelines, exercise, and school holidays.

KEYWORDS: Public Education, twentieth century, Rio Grande do Norte 


\section{INTRODUÇÃO}

Implantada a República no Brasil, um novo projeto político rapidamente fez-se sentir na educação escolar do País. Inaugurava-se um período de consolidação da responsabilidade do Estado para com a educação. A intensidade dos debates sobre o assunto concretizou-se na legislação da época. Em meio às mudanças a que os brasileiros assistiam, a escola primária destacou-se, sobretudo, no que diz respeito à institucionalização de um novo tipo de escola: os grupos escolares.

Escolas eminentemente urbanas, os grupos eram construídos com o intuito de oferecer um ensino unificado a um número maior possível de alunos; por meio deles, uma maior quantidade de crianças teria acesso aos mesmos conteúdos, métodos de ensino, materiais didáticos e diferentes orientações tendo em vista a formação de um novo cidadão (brasileiro e republicano). Além disso, foram marcados pelas particularidades arquitetônicas, responsáveis, em grande medida, pela identificação da escola primária pública como um lugar específico, próprio para a formação dos sujeitos. Este tipo de escola passava a ser considerado o modelo a ser seguido pelas demais escolas primárias. Entre outros aspectos, este tipo de instituição de ensino foi projetado para ter uma organização administrativa e pedagógica complexa, pautada em princípios de racionalidade científica.

Aspecto que também chama a atenção para essas instituições é a presença de preceitos de Higiene. Esse aspecto é relevante também devido à expansão de tais princípios para outras instituições escolares no início da República. Na passagem do século XIX para o XX, ideias higienistas atingiram diferentes esferas da sociedade brasileira. Na educação escolar influenciou na organização de instituições provocando alterações tanto na sua estrutura física quanto mesmo nas práticas escolares. As escolas primárias, com ênfase nos grupos escolares, tornaram-se difusores de preceitos de Higiene, entendida como medicina do social. Ao lado desses preceitos médicos, as discussões sobre métodos de ensino atingiram os grupos. A presença do chamado método de ensino intuitivo influenciou diretamente as vivências escolares tanto intra quanto extra classe, a exemplo das práticas com uso de diferentes recursos didáticos e dos passeis escolares.

Dessa forma, pensando nas práticas escolares dessas instituições de ensino a partir desses princípios, selecionamos algumas experiências dos grupos do Rio Grande do Norte. São elas: Passeios extraclasse, uso de materiais pedagógicos diversificados, orientações de Higiene, exercícios físicos, e, festas escolares.

\section{PRÁTICAS ESCOLARES}

\subsection{Passeios extraclasse}

Por meio desta investigação percebemos, entre as práticas escolares, aquelas voltadas para métodos de ensino considerados modernos, entre elas destacamos os passeios escolares. Analisamos suas características, princípios e finalidades. Tais atividades representaram mais um suporte para o processo de escolarização dos alunos do início do século XX, cuja aprendizagem era realizada pelo método intuitivo, conforme princípios modernos. 
Os passeios escolares eram meios para que as crianças apropriassem-se do mundo vivo, desenvolvendo sua capacidade de raciocínio e de construção do conhecimento. Os passeios foram, assim, uma prática intuitiva em termos metodológicos. $O$ ensino intuitivo se baseava no processo de educação pautado nos sentidos e na experiência.

Os passeios, como uma prática metodológica intuitiva, começavam a fazer parte de sistemas de ensino de diferentes países a partir do final do século XIX. Cardoso (2008) mostra em seu estudo, para citar alguns exemplos, que entre 1879 e 1897, tem-se registros da prática na França e na Espanha. A partir de 1904, de modo geral, os passeios escolares começam a ser registrados nas escolas primárias do México. Na Argentina estão presentes desde, pelo menos, os anos de 1910, conforme regulamentação do ensino.

No Rio Grande do Norte, a partir de 1913 por Regimento oficial, estava determinado para todos os grupos escolares e escolas isoladas: "[...] a obrigatoriedade dos passeios escolares mensaes, que se destinam não só á cultura physica dos alumnos como á aproveitosas licçoes de coisas." (A Republica, 20/04/1914, n. 86, p. 01).

No Rio Grande do Norte, todo professor deveria fazer uma descrição do passeio escolar, mostrando qual lugar seria visitado, quais os aspectos do lugar deveriam ser observados, o que continha em volta do ambiente, qual era a distância do local visitado para grupo escolar em que ministrava aulas, quantos alunos participaram do passeio, além de explicar ao que cada ambiente remetia. Por exemplo, se eles fossem visitar um lago em cujo entorno tivessem carnaúbas ou diferentes árvores, no lugar seria explanada a aula de geografia, que fazia com que os alunos pegassem com suas próprias mãos a areia e a água, aguçando seus conhecimentos pela natureza e seus fenômenos, mostrando também, os seus possíveis acidentes geográficos causados tanto pela natureza quanto pelo homem, como mostra o diretor do Grupo Escolar Tenente Coronel Correia, do Assú-RN, para o diretor geral da Instrução Pública, em 1914:

[...] Cumprindo o que dispõe o ar. 21 do Regimento Interno dos Grupos Escolares e Escolas Isoladas, levo ao vosso conhecimento que hotem, 10 de março, pelas 6 horas da manhan em companhia de todas as classes deste grupo, fiz um passeio escolar ao sitio -Mês Amours - distante deste local mais ou menos um kilometro, onde, á margem de aprazível lago, contornando de verdes carnaubaes, algodeiros e milharaes, explicamos às classes os termos geographicos, que ellas por suas próprias mãos, conduzindo areia em pequenas vasilhas, concretisaram, formando, com a dita areia, na agua rasa, ilhas, penisulas, cabos, isthmos, costas etc, emquanto ao mesmo tempo, o seu relevo deixava ficar bem representado, oceanogolfos, estreitos, etc.

Na mesma occasião, foi também dada uma explicação concretisada, sobre vulcão, despertando nos alumnos positivos interesses por conhececerem suas naturezas, erupções, etc.[...]. (Instrucção Publica. A Republica, 20/04/1914, n. 86, p.02).

A realização dos passeios escolares, além de momentos de aprendizagem relativas às disciplinas escolares, podia converte-se também em momentos de exaltação cívica e dos poderes instituídos da república em meio a processos de interação escolar e social. O encontro com autoridades e o canto de hinos patrióticos, por exemplo, remete a um processo formador para além da escolarização. Os alunos eram formados como sujeitos de um regime republicano e precisavam apropriar-se dos signos políticos da época. Ao lado de atividades cívicas presentes nos 
passeios, tinham espaço também uma série de atividades físicas (cânticos, corridas e jogos infantis).

Havia preocupação do governo republicano nos passeios como um meio de reforçar a aprendizagem dos alunos. Considerava-se que era a partir da observação, do contato com o ambiente, com a comunidade, que os alunos desenvolviam e produziam novos conhecimentos. Para o ambiente escolar do ensino primário público brasileiro do início do século XX, constituíramse em uma inovação pedagógica. As atividades extraclasses deveriam contar com a participação efetiva dos alunos, já que mesmo fora da sala de aula, eles deveriam aprender através da interação com o mundo, aspecto próprio do método intuitivo. Para essa interação os objetos escolares muito contribuíam e, mesmo os objetos da natureza, que em meio às ações escolares dos passeios transformavam-se também em objetos de estudo.

\subsection{Uso de materiais pedagógicos e escolares}

Considerados como escola moderna, os grupos eram organizados, de modo geral, por preceitos e práticas higienistas e o processo de escolarização baseava-se, especificamente, no método intuitivo. Para o êxito deste, toda uma gama de materiais pedagógicos e escolares era necessária. É nesse sentido que buscamos identificar a presença destes materiais nos grupos escolares norte-rio-grandenses.

Os materiais pedagógicos e escolares a que nos referimos compreendiam os recursos para o exercício do método intuitivo. Os materiais pedagógicos eram, por exemplo: os contadores mecânicos, a coleção de sólidos, o mapa do Brasil, o globo terrestre, os quadros negros, as tintas, os lápis, as folhas de mata-borrão entre outros objetos que auxiliassem os alunos diretamente nas atividades relativas às disciplinas escolares, ou seja, que contribuíssem para seu aprendizado. Já os materiais escolares eram, por exemplo: mesas, cadeiras, bancos-carteiras, escarradeiras, sineta, relógio de parede, entre outros objetos e aparelhos físicos que compunham a estrutura da escola dando, ao aluno, mais suporte e comodidade para aprender.

Esses materiais exerciam grande importância na vida de um indivíduo. Era a partir desses recursos que os alunos possivelmente, iriam construir sua percepção a respeito do que estavam estudando. Eles exercitariam sua escrita e desenvolveriam seu lado intelectual, já que teriam que responder aos exercícios propostos pelos materiais. Porém, não eram só os materiais pedagógicos que exerciam influência no modo de aprendizagem do aluno, o contato com objetos como móveis, estrados, relógios, pátio, corredor e biblioteca, como afirma Vidal (2009), também era um modo de aprendizado.

Há professores que relacionam as condições materiais da escola com êxitos ou fracassos nas condições de trabalho, especialmente, nas práticas de ensino junto aos alunos. Isso é característico da importância que a cultura material da escola tem sobre as práticas escolares. Assim, identificarmos os materiais, ou aspectos destes, que compunham os grupos escolares, significa percebermos aspectos relativos ao ensino ali ministrado e, portanto, da cultura escolar própria dos grupos. Esse processo de identificação não é pouco, se considerarmos que essa identificação leva-nos à compreensão de práticas escolares. A localização dos materiais no âmbito da cultura escolar, por sua vez possibilita-nos compreender, para além das práticas, o processo de apropriação de orientações e propostas pedagógicas assim como das reformas do ensino em vigor em determinado período, no nosso caso específico, no início do século XX. 
No Estado do Rio Grande do Norte havia preocupação no que diz respeito aos materiais pedagógicos que dariam melhores condições de ensino para a população. Um exemplo disso, podemos observar no regimento interno do Grupo Escolar Trinta de Setembro, na cidade de Mossoró-RN, em 1909, que assim declarava:

Material escolar e livros didacticos

Art. 61. - Os moveis e utensilios scolares deverão cingir-se aos modelos que facilitem a vigillancia do professor, a responsabilidade individual do alumno e a satisfaçao dos preceitos hygienicos e pedagogicos. Para este fim serão observadas as seguintes regras:

a) os bancos serão feitos de modo que possam os alumnos sentar se posicionar os pés sobre o chão, tendo as pernas perpendiculares a este, as coxas em angulo recto com as pernas, e o tronco em angulo recto com as coxas; b) o assento terá uma ligeira inclinação de deante para traz, devendo ter o encosto altura sufficiente para apoiar a região lombar;c) as carteiras serão proporcionaes á estatura dos alumnos; d) os móveis serão dispostos na sala conforme a projecção da luz, devendo os meninos recebel-a do lado esquerdo e do alto. [...]. (RIO GRANDE DO NORTE. Regimento Interno do Grupo Escolar "Trinta de Setembro, 1909).

Esses objetos pedagógicos, tão essenciais para o ensino intuitivo deveriam ser o quadronegro, com giz colorido e branco, livros para leitura para o mestre, mapas para o ensino de Aritmética, entre outros objetos que deveriam estar nos grupos escolares, conforme o regimento interno dos grupos escolares e escolas isoladas do Rio Grande do Norte, em 1914.

Já os materiais escolares, como as carteiras, de acordo com Castro e Silva (2011, p. 209) deveriam corresponder ao comportamento que o aluno deveria ter no ambiente escolar, elas lhes ensinavam a ser disciplinados, a moldar uma higiene corporal, além de dar conforto no processo de aprendizagem, principalmente, quando elas se tornaram indispensáveis para escrever:

[...] na cena escolar [...]. Bancos e cadeiras ordenavam espaços e sujeitos dentro de um universo delimitado. Na escola, mesa e cadeira encontraram força singular que as transformaram em objetos com atuação direta na higiene do corpo, na disciplina, no conforto e na aprendizagem. Perpetuaram-se como objeto fundamental para um bom ensino. Algumas delas, no entanto, ganharam um real espaço no ensino quando se tornaram necessárias como apoio para escrever, pois até então ensinava-se, primordialmente, a ler. (CASTRO e SILVA, 2011, p. 209).

Por tudo isso foram construídas carteiras que continham a altura ideal entre o assento e a mesa, muitas delas importadas de outros países, pois acreditava-se que elas seriam as mais adequadas ao desenvolvimento do ensino, sem proporcionar grandes malefícios à saúde dos alunos, já que os pés das carteiras deveriam ser fixada ao solo para evitar possíveis deslocamentos prejudiciais a saúde do aluno, como afirma Vidal (2009, p. 34):

Surgiram, assim, as carteiras que, além de regularem a altura ideal entre o assento e a mesa, normatizavam a distância entre o encosto do banco e o borde da mesa e a inclinação desta última. Com um ou dois lugares, as carteiras, feitas com pé de ferro fundido, deveriam ser fixas ao solo para evitar que seu deslocamento causasse outros danos à saúde do escolar. 
De acordo com o Dr. Nestor dos Santos Lima, em 1926, no Relatório do Departamento de Educação, o mobiliário norte-rio-grandense foi fabricado em Natal pela Serraria Industrial Limitada, dando a entender que além do material pedagógico fornecido aos grupos escolares à custa do Estado, a mobília deveria ser adequada ao aluno de modo a dar mais comodidade e conforto para eles consequentemente terem um bom aprendizado: "[...] teem mobiliario novo fabricado nesta capital pela Serraria Industrial Limitada e possuem todos material pedagogico fornecido pelo Departamento e á custa do Estado. [...]" (LIMA, 1926).

Pesquisar sobre materiais pedagógicos e escolares proporciona-nos condições de compreender a cultura escolar de uma época e as relações entre diferentes momentos da organização da educação escolar pública do País. Como bem afirma Souza (1998, p. 224), "o aparecimento, uso, transformação e desaparecimento dos objetos escolares são reveladores das práticas educacionais e suas mudanças". Como já afirmamos, os grupos escolares, considerados escolas modernas e detentoras de um ensino primário renovado, requeriam uso de uma grande quantidade e variedade de materiais pedagógicos e escolares muitos daqueles sugeridos pelas autoridades do ensino podem ter tido vida curta ou nem mesmo chegado aos grupos do Rio Grande do Norte, a exemplo, das cartas de Parker, não localizadas na documentação analisada para esta pesquisa ou dos museus escolares com aparecimento mínimo nas fontes.

Os grupos escolares foram acompanhados de uma nova concepção de arquitetura escolar e de exigências próprias de uma escola moderna. Souza $(1998$, p. 16) lista exemplos de tais exigências com base na pedagogia moderna: "classes, bibliotecas, museus, laboratórios, oficina, ginásios, pátios para recreio, auditórios", além de "uso de novos materiais escolares, outro tipo e mobília escolar abundante material didático". Opinião similar a esta encontramos em Moura e Barros (2007, p. 3) quando afirmam que: "[...], com o advento dos grupos escolares, a materialidade escolar, até então, praticamente inexistente, teve de ser incrementada para corresponder aos ideais aspirados para a época como a disciplina, a ordem, o patriotismo e a civilidade".

Ao investigarem a cultura material do Grupo Escolar Capitão-Mor Galvão, em Currais Novos-RN, Moura e Barros (2007) declaram a importância alcançada pela estrutura arquitetônica da instituição associada ao seu mobiliário escolar, composto por móveis específicos seja para a sala da direção, como escrivaninhas de metal e armários de madeira, seja para as salas de aula, como quadros de giz, bancos-carteiras e estrados. Nas palavras das autoras:

[...], abraça-se definitivamente a causa de se dispor para a escola um espaço real, caracterizado por atividades específicas e equipado, igualmente, de forma específica. Nessa nova ordem estética, ganha destaque o material permanente de cunho didático-escolar, como mapas, globos, instrumentos de medicação e demais outros, bem como os destinados a ensinamentos importantes como o cuidado com a imagem e a inculcação de novos valores, como mastros, bandeiras, escudos, fotos. (MOURA e BARROS, 2007, p. 7).

No Grupo Escolar Joaquim Correia, em Pau dos Ferros-RN, no ano de 1911, apesar do mobiliário ser suficiente e de boa qualidade, havia a ausência dos materiais pedagógicos. Porém, segundo o inspetor de ensino Amphiloquio Câmara, eles corresponderam bem ao processo de ensino dos alunos (CÂMARA, 1911, p. 01). 
No Grupo Escolar Senador Guerra, da cidade de Caicó-RN, em 1917, era perceptível o destaque, nos registros dos jornais, da ausência de materiais pedagógicos e as desagradáveis condições de higiene e conforto às quais os alunos e o edifício se encontravam. Sendo assim, a falta tanto dos materiais quanto da higiene poderiam provocar doenças nos alunos afetando seus organismos e sua saúde, algo que não estava de acordo com os preceitos higienistas:

Infelizmente, continuam a perdurar a falta da material pedagogico e as desagradaveis condições de conforto e hygiene do edificio, notadamente o ladrilho que, alem de damnificado, desprende grande quantidade de pò, por occasião dos exercícios escolares,

$E^{\prime}$ evidente que a poeira è a causa de innumeras enfermidades, inclusive a tuberculose que ocupa logar de preferencia nos males do organismo humano.

Já tenho observado que as crianças, quando for por occasião dos exercicios escolares recebem o pò do tijollo, são accommettidas de tosse não raras vezes violenta. (GONZAGA, Francisco. Pelo ensino - visitas escolares - Grupo Escolar Senador Guerra. A Republica. Natal, 18/09/1917, n. 206, p. 02).

Mesmo que estivesse decretada a necessidade de se ter estes materiais, em alguns grupos escolares, isso não ocorreu. Os materiais pedagógicos não eram tão bem conservados e a sua quantidade era insuficiente. Regimentos de ensino e realidades escolares nem sempre caminharam de mãos dadas. É uma contradição observarmos as relações entre o instituído e o efetivado nos grupos escolares, instituições como um marco moderno do governo republicano no Brasil.

\subsection{Exercícios físicos}

O método intuitivo, considerado moderno, higiênico e progressista, influenciou o currículo escolar tanto no que se refere às matérias de ensino quanto às práticas docentes que demarcavam o cotidiano das escolas. Foi nesse contexto que a prática de exercícios físicos passou a ser considerada e vivenciada em instituições públicas de ensino primário de forma cada vez mais planejada e frequente.

Mudanças nos métodos de ensino proporcionaram também mudanças no trato com o corpo - A construção de espaços específicos para as instituições de ensino primário (grupos escolares) tem influência direta sobre a escolarização dos corpos das crianças, higienizando-os e definindo e mesmo hierarquizando relações entre os sujeitos. Pela estrutura física dos edifícios escolares percebemos mecanismos de disciplinarização corporal, os quais levavam as crianças a introjetarem noções de ordem, hierarquia, disciplina e de gênero.

A escolarização nos grupos escolares era, portanto, também dos corpos. Ganha espaço nos grupos, a prática da ginástica. Como uma prática escolar seguiu o exemplo, principalmente, da ginástica sueca criada no início do século XIX: pedagógica, militar, médica e estética. A ginástica passou a ser obrigatória no Rio Grande do Norte, como podemos observar na Lei Orgânica do ensino no Rio Grande do Norte, n. 405, de 29 de novembro de 1916.

Com o propósito de educar e escolarizar o corpo dos alunos dos grupos escolares, os exercícios físicos se tornaram uma prática escolar instituída ao longo dos anos. Daquela escola 
primária do início do século XX, podemos encontrar as raízes da constituição da disciplina escolar Educação Física dos dias atuais. A associação dos exercícios físicos com os hábitos higiênicos estava na base de um processo de civilização dos corpos dos alunos. Mas, também dos mestres e das mestras.

A escolarização dos corpos não estava presente apenas nas atividades intituladas de exercícios físicos. A atenção aos corpos dava-se ao longo da dinâmica escolar por meio de outras práticas escolares já institucionalizadas, a exemplo do recreio (diário) e dos passeios extraclasse (mensais) e mesmo disciplinas, como "Trabalhos Manuais". A centralidade da atenção aos corpos imersa na cultura escolar constituiu-se em alvo de atenção de intelectuais e administradores públicos das primeiras décadas da República. No Rio Grande do Norte isso não foi diferente.

Nesse sentido, podemos citar outra prática voltada para a educação do corpo e o seu tratamento específico - a escrita e a sua necessidade de adoção de postura específica para a promoção da escrita vertical. Associada à busca por uma melhor e mais higiênica prática de escrita e de leitura estava, obviamente, a preocupação com o mobiliário, considerando-se a busca por hábitos saudáveis para a sociedade.

Verificamos a concretização de um processo constitutivo de uma corporeidade escolar, marcando a cultura escolar das instituições de ensino primário da passagem do século XIX para o $X X$, baseado no estabelecimento de vivências que envolviam aspectos sociais, biológicos, psicológicos e educacionais.

Verificamos que, por meio da escola primária, uma série de mecanismos, instrumentos e práticas foram estabelecidos tendo em vista a escolarização dos corpos de crianças, futuros cidadãos de um Brasil republicano, assim como de adultos (profissionais com atuação nas escolas), cuja atuação na sociedade (ensino escolar) davam-lhe o estatuto de sujeitos formadores de um novo tempo (republicano e moderno).

\subsection{Higiene}

Representações em torno da higiene escolar contribuíram para reforçar valores relacionados a comportamentos considerados civilizados. As pretensões higiênicas estavam para além da escola primária. Esta seria um dos veículos divulgadores dos preceitos higienistas do final do século XIX para início do XX. Passava a ser tarefa da escola primária, eliminar atitudes consideradas viciosas nos alunos e, ao mesmo tempo, criar hábitos higiênicos.

A construção dos grupos escolares pode ser associada a um projeto mais amplo de intervenção nas práticas sociais, em grande medida pela difusão dos preceitos médicos que a orientavam. Sob a denominação de higiene, um ramo da medicina voltada para o "social", de caráter preventivo, vários aspectos da educação escolar foram repensados. Conforme Vago (1999, p. 93), "a ideia de reunir as escolas isoladas em um único e específico prédio escolar teve como um de seus suportes a preocupação obsessiva com preceitos de higiene, que, da arquitetura à distribuição do tempo, do programa de ensino ao código de disciplina, da diretora à servente, deveria atingir os corpos das crianças".

Com base nesses princípios de higiene, Moura e Barros (2007) identificaram no Grupo Escolar Capitão-Mor Galvão, em Curais Novos-RN, no início do século XX, uma série de materiais que compunham o cenário escolar. Segundo as autoras (2007, p. 6): 
Quanto a essa particularidade de se obter um rigor quanto ao asseio, consta no Inventário do Capitão-Mor Galvão a presença de materiais como lavatórios, escarradeiras, lixeiras, bacias de flandres, jarras, toalhas, baldes, vassouras, desinfetantes, espanadores, cantareiras de ferro, salvas (bandejas) de ágata e esponjas para limpar os quadros de giz. Vale salientar que todo esse arsenal patenteou um conjunto de normas profiláticas condizentes com os princípios que deram vigor ao ideário de modernidade em torno da Primeira República, [...].

Souza (1998, p. 143) ressalta que "[...], as representações em torno da higiene escolar contribuíram para reforçar valores morais relacionados a padrões de comportamento considerados civilizados". Dessas representações e dos próprios preceitos higienistas criava-se a ideia de corpo civilizado, sadio e moralizado. De acordo com médicos higienistas da época, os "inimigos" do corpo civilizado ou do "corpo social", como prefere Herschamnn (1994, p. 49), "eram os 'excessos' e 'desvios'; era preciso, portanto, disciplinar a sociedade, incutir valores, destruindo, desse modo, os 'vícios' e as 'perversões' que tanto ameaçavam os centros urbanos [...]". As pretensões higiênicas estavam para além da escola primária. Esta seria um dos veículos divulgadores dos preceitos higienistas do final do século XIX para início do XX. Passava a ser tarefa da escola primária,

Eliminar as atitudes viciosas e inculcar hábitos salutares, desde a mais tenra idade. Criar um sistema fundamental de hábitos higiênicos, capaz de dominar, inconscientemente, toda a existência das crianças. Modelar, enfim, a natureza infantil, pela aquisição de hábitos que resguardassem a infância da debilidade e das moléstias (ROCHA, 2003, p. 179).

A presença de preceitos higienistas nos grupos escolares, como vimos, não marcou apenas as práticas relativas ao asseio dos ambientes e dos corpos neles inseridos. A higiene teve ramificações nas próprias práticas pedagógicas por meio de orientações consideradas científicas para a produção de materiais pedagógicos e mobiliário escolar. Essa presença não está ligada apenas a uma racionalidade pedagógica. Ela se relaciona, também, a uma racionalidade política e social, no sentido de buscar a formação de uma sociedade disciplinada com ares de urbanização e civilidade. Ao se referir à relação entre higiene e grupos escolares, Amorim (2013, p. 58) afirma que:

A intervenção da área médica não se dava apenas nas práticas higiênicas do cotidiano escolar, mas intervinha também na prática pedagógica orientando sobre qual material didático a ser usado; a melhor maneira de sentar-se na cadeira para escrever; a melhor distância do quadro, largura e altura das carteiras, enfim, tudo era orientado através do campo médico almejando a prevenção de doenças, introdução de cuidados com a saúde prevendo a formação de cidadãos fortes e saudáveis. Logo, podemos observar que o material pedagógico também era do conhecimento do campo médico que realizava pesquisas e orientava na confecção bem como na compra e na forma de uso desses materiais para que fossem utilizados da melhor maneira para não comprometer a saúde da sociedade escolar que fazia o uso dele.

As preocupações higienistas localizavam-se no bojo das discussões sobre modernidade. Esta levada para a esfera da administração pública e do Estado, contou não apenas com a intervenção médica. Herschamnn (1994, p. 44) salienta que, ao lado dos médicos é preciso considerarmos o papel dos engenheiros e dos educadores. Opinião similar à de Kropf (1994, p. 
222), segundo a qual, "[...]. Guardadas as devidas particularidades e diferenciações nos discursos desses intelectuais reformadores, pretendia-se legitimar um programa social de modernização [...]". O papel dos educadores foi evidente, por exemplo, na defesa dos métodos de ensino modernos, com destaque, no Brasil da passagem do século XIX para o XX, para o que se convencionou chamar de método intuitivo. $O$ ensino nos grupos escolares era pautado por tal proposta metodológica, que veio a se constituir em uma das bases da cultura escolar do início do século XX.

\subsection{Festas}

As festas escolares foram fundamentais para estabelecer relações políticas, sociais e culturais, já que elas marcavam uma série de eventos que aconteciam tanto nos grupos escolares como fora deles, ou seja, nas ruas, praças e espaços públicos que envolviam a sociedade. Seu objetivo era de interagir e de compartilhar da celebração do civismo, proposto pelo governo republicano com os seus ideais de pátria, ordem e progresso, com o intuito de nas festas escolares, esses ideais se espalharem além das salas de aula. Como mostra o registro do Grupo Escolar Augusto Severo, do jornal "A Republica" de 1911, é perceptível ver que as festas escolares estabeleciam uma relação com toda a sociedade, a fim de que tanto os alunos como toda a população celebrassem o civismo, o patriotismo e as atividades realizadas nos grupos escolares, além de entoarem o hino antes e depois da abertura das festas, fazendo dele, um objeto disciplinador para a comunidade em geral:

No Grupo modelo Augusto Severo, será tambemcommemorado festivamente a data da nossa independência, com um passeio civico pelas ruas da capital ás $41 \backslash 2$ horas da tarde, realizando se ás $61 \backslash 2$ horas da noite, no edifício do mesmo grupo, uma sessão cívica, que constara de recitativos e allocunções patrióticos pelos alumnos e pelo director e exercícios physicos dos três cursos sob a direcção dos respectivos professores.

$\mathrm{Na}$ abertura as sessão será cantado o Hymno nacional e o ser encerrado o Hymno da independência, por todos os alumnos do grupo. (NO GRUPO Escolar <Augusto Severo>. A Republica. Natal, 06 de set. 1911, n. 191, p. 01).

As festas escolares serviam como um meio disseminador dos ideais republicanos. Eram impregnadas do espírito patriótico e de civismo ao qual a sociedade deveria ter. Os desfiles dos alunos uniformizados representavam o que estava ocorrendo dentro dos grupos escolares, com o intuito de mostrar a toda população os feitos que o governo estava proporcionando em torno da educação. Sendo assim, os grupos escolares eram a vitrine do governo republicano em que tudo que era realizado dentro deles deveriam ser disseminados para a sociedade através das festas escolares.

Em algumas festas escolares, as autoridades faltavam por justa causa. Porém, não deixaria de ter a festa, comparecendo o corpo docente e discente do grupo escolar ou escola normal para comemorar o ato festivo da qual iria festejar, como mostra o registro do Jornal "A República", de 1922:

Ante-hontem, a Escola Normal e o grupo escolar "Augusto Severo", commemoraram, com uma sessão cívica, presidida pelo dr. Manoel Dantas, 
director da Instrucção Publica. ocentenario do decreto prohibindo a vinda de tropas portuguezas para o Brasil, que foi o passo principal para a proclamação da Independencia.

O dr. Nestor Lima não poude comparecer, por justo motivo, comparecendo porem, os corpos docente e discente da Escola Normal e do Grupo Escolar.

Hasteada a bandeira com as formalidades da pragmática e reunidos todos no saalão de festas, o professor Aprigio Camara fez uma bella e erudita conferencia, muito applaudida.

A sessão terminou com o hymno nacional cantado por todos os alumnos. (AS Festas do Centenario. A Republica. Natal, 03 de ago. 1922, n. 170, p. 01).

De acordo com Maia (2012) existiam três tipos de festas escolares: as festas cívicas, solenes e recreativas. As festas cívicas faziam alusão aos fatos e vultos históricos relacionados à pátria, tais como: o Descobrimento do Brasil, o Dia do Soldado, o Dia da Bandeira, o Dia 07 de Setembro (Festa da Pátria).

As festas solenes representavam a comemoração da entrega dos certificados de conclusão do ensino primário em que se faziam presentes os alunos, os funcionários, autoridades e políticos que faziam discursos e, em alguns casos, uma breve visita ao edifício do grupo escolar; além de comemorar a inauguração dos grupos escolares e do encerramento do ano letivo, como se pode observar no Grupo Escolar Modelo Augusto Severo, em 1925:

[...] Entre a 1a e 2a parte deu-se a entrega dos certificados de Estudos Primarios Superiores ás alumnas do $2 \circ$ anno complementar que terminaram o curso.

Ao piano fez o acompanhamento de todos os hymnos e canções a professora $d$. Julia Barbosa.

Os que assistiram á excellente festividade de encerramento do annolectivo do grupo <Augusto Severo> colheram a melhor impressão da orientação que the imprimem os seus professores, assim como do aproveitamento dos alumnos que frenquentam as suas aulas. (FESTAS Escolas no dia 19 - Grupo Escolar Modelo "Augusto Severo". A Republica. Natal, 24 de nov. 1925, n. 256, p. 01).

E as festas recreativas que tinham o objetivo de divertir a comunidade escolar e, às vezes, arrecadar fundos, como ocorria nas festas de São João. No Grupo Escolar Augusto Severo, em 1922, a festa foi realizada, como nos mostra o Jornal "A Republica", com distribuição de prêmios e entrega de ramalhetes de flores ao Diretor do Departamento de Educação, Nestor Lima:

[...] No salão de festas sob a presidencia do dr. Antonio de Souza, realizou-se a parte recreativa, com a distribuição de premios sendo conferida a medalha de ouro, como premio especial á alumna Adelia Soares Teixeira, que se distinguiu no concurso de declamação das festas do Centenario.

Os alunos offereceram ao dr. Nestor Lima, bello ramalhete de flores naturaes, que s. s, por sua vez, offertou ao Governador do Estado. [...] (A Festa da Bandeira. A Republica. Natal, 21 de nov. 1922, n. 257, p. 01). 
As festas escolares foram fundamentais para estabelecer relações políticas, sociais e culturais, já que elas marcavam uma série de eventos que aconteciam tanto nos grupos escolares como fora deles, ou seja, nas ruas, praças e espaços públicos que envolviam a sociedade. Seu objetivo era de interagir e de compartilhar da celebração do civismo, proposto pelo governo republicano com os seus ideais de pátria, ordem e progresso, com o intuito de nas festas escolares, esses ideais se espalharem além das salas de aula.

As festas escolares não eram só comemorações de datas patrióticas, solenes e recreativas. Elas exerciam sobre a população um ideal de que seria possível desenvolver o seu país de acordo com o lema republicano de "Ordem e Progresso", fazendo com que fossem espalhados pela sociedade, a disciplina, o civismo e a moral instituído pelo governo republicano.

\section{REFERÊNCIAS}

1. AMORIM, Hananiel de S. Higiene e escolarização nos grupos escolares no Rio Grande do Norte nas primeiras décadas do século XX. Monografia [Bacharelado em História]. Natal, Universidade Federal do Rio Grande do Norte, 2013.

2. CÂMARA, Amphiloquio. A reforma da intrucção - Os Grupos Escholares. A Republica. Natal, 09/02/1911, n. 32, p. 01

3. CARDOSO, Carlos A. de A. Um ponto de vista geográfico nos manuais didáticos brasileiros: os passeios e as excursões escolares. Revista da Casa da Geografia de Sobral, Sobral, v. 10, n. 1, p. 93-105, 2008.

4. CASTRO, Raquel Xavier de Souza; SILVA, Vera Lucia Gaspar da. Cultura material da escola: entram em cena as carteiras. Educar em Revista, Curitiba, Brasil, n. 39, p. 207-224, jan./abr. 2011. Editora UFPR.

5. GONZAGA, Francisco. Pelo ensino - visitas escolares - Grupo Escolar Senador Guerra. A Republica. Natal, 18/09/1917, n. 206, p. 02

6. HERSCHAMNN, Micael M. A arte do operatório - Medicina, naturalismo e positivismo. IN:___ _ PEREIRA, Carlos Alberto M. (Org.). A invenção do Brasil moderno: medicina, educação e engenharia nos anos 20-30. Rio de Janeiro: Rocco, 1994, p. 43-65.

7. KROPF, Simone P. O saber para prever, a fim de prover-a engenharia de um Brasil moderno. IN: HERSCHAMNN, Micael; PEREIRA, Carlos Alberto M. (Org.). A invenção do Brasil moderno: medicina, educação e engenharia nos anos 20-30. Rio de Janeiro: Rocco, 1994, p. 202-223.

8. LIMA, Nestor dos S. Relatório do Departamento de Educação apresentado pelo Dr. Nestor dos Santos Lima. Natal, 15 set. 1926. 43 fl. (Manuscrito).

9. MOURA, Gracielle C. F. ; BARROS, Eva C. A. C. Cultura material escolar: o Grupo Escolar CapitãoMor Galvão e a formação de crianças sob um ideal de ordem e civilidade (1912-1930). In: ENCONTRO DE PESQUISA EDUCACIONAL NORTE E NORDESTE, 18‥ Anais. Maceió, UFAL, 2007.

10. ROCHA, Heloisa Helena P. A higienização dos costumes: educação escolar e saúde no projeto do Instituto de Hygiene de São Paulo (1918-1920). Campinas: Mercado de Letras; São Paulo: Fapesp, 2003.

11. SOUZA, Rosa Fátima de. Templos de civilização: a implantação da escola primária graduada no estado de São Paulo (1890-1910). São Paulo: Fundação Editora da UNESP, 1998. 
12. VAGO, Tarcísio Mauro. Cultura escolar, cultivos de corpos: educação physica e gymnastica como práticas constitutivas dos corpos de crianças no ensino público primário de Belo Horizonte (1906-1920). [Tese de Doutorado]. Bragança Paulista, USF, 1999.

13. VIDAL, Diana Gonçalves. No interior da sala de aula: ensaio sobre cultura e prática escolares. Currículo sem Fronteiras, v.9, n.1, pp.25-41, Jan/Jun 2009. 